\title{
Assessment of Community Health and Health Related Problems in Debre Markos Town, East Gojjam, Ethiopia, 2013
}

\author{
Belayneh Kefale Gelaw ${ }^{1 *}$, Gobezie Temesgen Tegegne ${ }^{1}$ and Yeshanew Asinake Bizuye ${ }^{2}$
}

${ }^{1}$ Department of Pharmacy, College of medicine and Health Sciences, Ambo University, Ambo, Ethiopia ${ }^{2}$ Debire Markose Hospital, North East Ethiopia, Ethiopia

\begin{abstract}
Community Based Training is an on-site training program tailored to an employer's specific hiring needs. The training takes place in the actual work area in the workplace, and a professionally trained job coach is located on-site to provide additional support in training. The study was conducted in Keble 05 Debre markos town found in Amhara region, East Gojjam Zone, which is located $299 \mathrm{~km}$ for away from Addis Ababa and $265 \mathrm{~km}$ away from Bihar Dar town. The Administration has 8 sefer the keble has 8551 population of these 4447 were female and 4104 male, its climate condition, woynadega and had 45 government and private health institution. The aim of the study was to assess the community health status and health related condition in Keble 05 Debre Markos town, East Gojjam Zone, Ethiopia, 2013.
\end{abstract}

Method: Community based cross sectional survey conducted from 25/08/2013-24/09/2013 by using interviewer administrative questioner and observation. The study conducted in urban population Keble 05 Debire markos town.

Result: The cross sectional descriptive study, $94 \%$ of house hold in the keble had latrine facility Among this $50 \%$ of house don't have hand washing facility connected with latrine among women who were pregnant $100 \%$ were attained at least $1^{\text {st }} \mathrm{ANC}$ and 90 of them deliver in the health facility from breast feeding $18 \%$ of children stop breast feeding before the age of 6 month and early and late feeding also present in $9 \%$ of children.

Conclusion: Most of the house hold in the kebel had latrine constructed but most of them had no hand washing facility connected with latrine and low coverage of solid and liquid waste disposal system. There were also different problems like low immunization coverage's, low family planning, utilization poor wining and exclusive breast feeding.

Keywords: Debre Markos; Kebele; Latrine; Sanitation; Community health; ANC; PNC

Acronyms and Abbreviations: ANC: Antenatal Care; CBE: Community Based Education; CBTP: Community Based Training Program; CDI: Community Directed Intervention; EDHS: Ethiopia Demographic Health Survey; EPI: Expanded Program of Immunization; HEP: Health Extension Program; HC: Health Center; HP: Health Post; IUCD: Intrauterine Contraceptive Device; $\mathrm{MCH}$ : Maternal and Child Health; MDG: Millennium Development Goal; ORS: Oral Rehydration Salt; PAB: Prevention at Birth; PMTCT: Prevention of Mother to Child Transmission; PNC: Postnatal Care

\section{Introduction}

\section{Community based training program}

Community Based Training is an on-site training program tailored to an employer's specific hiring needs. The training takes place in the actual work area in the workplace, and a professionally trained job coach is located on-site to provide additional support in training [1]. CBTP (community based training program) is one parts of community based education (CBE) which is designed to train health science students, about community diagnosis to identify the problems related to health in the community, it provide health science students to apply the theoretical knowledge in to practical application.

Sustaining a healthy community is the goal of every part of the world. However, achieving this goal requires careful planning and organized community members, health organizations, academic institutions, and various government agencies. Although, in terms of education, technology, health resources, and per capita purchasing power are higher in United States, it fails to deliver the best health care at a reasonable cost. About 45 million (15.6\%) US population is not covered by health insurance [2]. The United States, which spends $16 \%$ of its GDP on health care, spends more on health care per capita than any other industrialized country. For example, Switzerland and Germany (which also spend a relatively high percentage of their GDP on health care) each spend $11 \%$ of their GDP on health care [1].

Neglected populations living under poverty throughout the developing world are often heavily burdened by communicable and non-communicable diseases, and are highly marginalized by the health sector due to their limited access to health and social support services [3]. The population density and diversity of urban communities offers formidable challenges for healthcare delivery. The constant mobility (within urban areas, rural-urban-rural cycles) further complicates the delivery of appropriate health interventions. The current approaches and systems in urban areas are unable to reach agreed-upon goals and targets (e.g., the MDGs, RBM, national targets) [4]. Without improved delivery of health services, the present obstacles - accessibility, affordability and utilization of the health systems-will perpetuate disparities and likely increase the risk factors, incidence and

*Corresponding author: Belayneh Kefale Gelaw, Department of Pharmacy, College of medicine and health science, Ambo University, P.O.Box 19, Ambo, Ethiopia, Tel: +251913805290/+215921250521; E-mail: belayneh.kefale@yahoo.com

Received November 25, 2014; Accepted December 10, 2014; Published December 12, 2014

Citation: Gelaw BK, Tegegne GT, Bizuye YA (2014) Assessment of Community Health and Health Related Problems in Debre Markos Town, East Gojjam, Ethiopia 2013. J Biosafety Health Educ 2: 125. doi:10.4172/2332-0893.1000125

Copyright: $\odot 2014$ Gelaw BK, et al. This is an open-access article distributed under the terms of the Creative Commons Attribution License, which permits unrestricted use, distribution, and reproduction in any medium, provided the original author and source are credited. 
prevalence of treatable and manageable health conditions as the size of vulnerable and marginalized urban populations grows. Reduction in disease burden would enable these communities and groups to become more economically active and, thereby, further reduce the socioeconomic factors contributing to disease occurrence.

Achieving reduction in disease burden lies in ensuring available health interventions reach at risk. Many simple, affordable and effective disease control measures have had limited impact due to poor access especially by the poorer populations (urban and rural) and inadequate community participation [5]. 'Community Directed Interventions (CDI) for major health problems in Africa' was found to be effective and efficient thus providing overwhelming evidence for its use as a strategy in delivering multiple interventions at the community level in rural Africa should be mandatory [6]. There is thus a need to test the feasibility, acceptability and effectiveness of the CDI strategy.

During 2011-12, the World Health Organization's Special Programme for Research and Training in Tropical Diseases (TDR) sponsored a multi-country situation analysis in four large and medium-sized urban settings throughout Africa-including Ghana (Bolgatanga, Wa), Liberia (Monrovia), Nigeria (Ibadan) and the Democratic Republic of Congo (Kinshasa) - to explore the feasibility of the CDI approach in addressing multiple disease intervention in urban communities [7].

\section{Statement of the problem}

Ethiopia is one of the developing country in which most of its population (85\%) mainly depends on agricultures [8]. Different factors like lack of professional committeemen, population awareness about the problems of waste disposal, adequate and necessary medical equipment, in accessible health facility and low health seek behavior leads to the community to have low health status.

Communicable dieses, nutritional problems, maternal and child health problems are the major challenging health care related problems in Ethiopia.

Even though the sanitary coverage of this zonal town was relatively higher, there is still lack of proper utilization of latrine [9]. The town municipality has attempted to manage the solid and liquid waste by converting in to compost for agricultural activities. Although the above measure has been taken, there is a problem in collection, transportation, and disposal of wastes on time as a result this the community is exposed to different communicable disease.

\section{Justification of the study}

As most of health related problems in Ethiopia are preventable, community health assessment is an important tool to identify health status, health related problems, and factors that could affect the society's health. The result of this survey can be used by governmental and non-governmental institutions to solve the community health related problems. This study can also be used as a base line data for further study (Figure 1).

\section{Objective of study}

General objective: To assess community health and health related problems in Keble 05 Debre markos town, East Gojjam Zone, Amhara, Ethiopia, 2013.

\section{Specific objective}

- To assess socioeconomic status of the community

- To assess environmental health and sanitation condition of community

- To assess MCH status of community

- To assess major morbidity statues of communicable disease

\section{Methodology}

\section{Study area and period}

Debre Markos is a capital city of East Gojjam Zone. It was established around 1852. Its name was menkorer. It is $299 \mathrm{~km}$ away from Addis Ababa, capital city of Ethiopia. Debre Markos town consists of 7 Keble's. It has 86,786 populations, of which 41,618 are male. It has an altitude of $2420 \mathrm{~m}$ above sea level with annual rainfall of $1380 \mathrm{~mm}$ and average temperature is $16^{\circ} \mathrm{C}$. The weather condition of Debre Markos town is Woynadega. In Debre markos town, there are $17 \mathrm{KG}, 23$ primary school, 2 high school, 1 preparatory, 15 adult

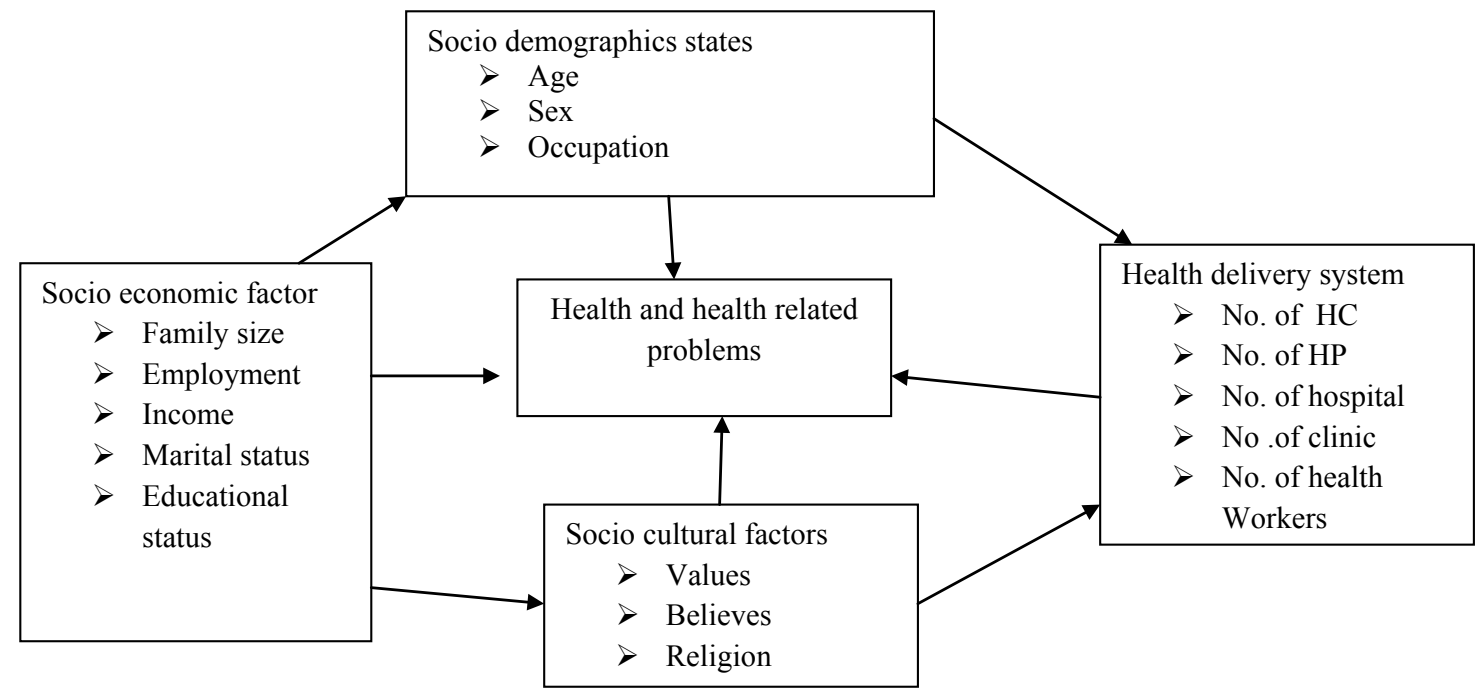

Figure 1: Conceptual Framework 
education schools, 11 different colleges and one University. It has also 1 Hospital, 3 health center, 7 health post, 21 private pharmacy, 11 private clinic, 2 diagnostic laboratory, and 13 traditional healers, which are from different professional expertise. The study was conducted in Debre Markos town Keble 05. The study was done from 25/08/2013$24 / 09 / 2013$

\section{Study design}

A community based descriptive cross sectional survey was conducted.

\section{Population}

- Source population- our source of population was all people who live in Debre Markos town,

- Study population- all population who live in Keble 05 .

- Study unit- The representative of household

- Sampling unit- house holds

\section{Inclusion and exclusion criteria}

- Inclusion criteria: The house hold of the study in keble 05 Debre Markos town

- Exclusion criteria:

- Individual who were seriously ill

- A house hold members who lived for less than 6 month in town

- Absence of household's members during visit.

\section{Sample size determination and sampling techniques}

Among the 7 Kebles of Debre Markos town administration, kebele 05 was selected by lottery method (probability sampling techniques).

Systematic sampling technique, which was taken in 8 house hold intervals, was used.

\section{Variables of the study}

- Dependent variables

- Hygiene and sanitation problems

- Maternal and neonatal, child health problems

- Major communicable disease and morbidity and mortality problems.

- Independent variables

- Health care delivery system

- Socio economic states of the population

- Educational status

- Socio cultural factors

- Demographic factors sex, age, religion.

\section{Data collection tool}

The data was collected by using structured questionnaire and an interview. The questionnaire consists of socio demographic situation, environmental sanitation, mother and child health and diseases condition in the house hold. The interview was undertaken among nine households for one hour in environmental sanitation, mother and child health and diseases condition in the house hold.

\section{Data quality management}

To ensure quality, data were cheeked for completeness, accuracy, clarity, and consistency by the principal investigator. The structured questionnaire was translated to their local language (Amharic).

\section{Data processing and analysis}

Tally sheet was used to analyze the data. The results were presented in tables and graphs.

\section{Ethical considerations}

Approval and permission was sought from Ethical Review Board of College of medicine and health Sciences of Debre Markose University. An official letter of cooperation was written from the Department of Pharmacy to Debre markos woreda Keble 05 administration office to obtain their consent the necessary explanation about purpose of the study and its procedures was done informed consent was also avils from each respondents. Unwilling participants in the study ware not encountered more over any omission was not present to ensure confidentiality anonymous interviewer was conducted.

\section{Operational definition}

- Traditional birth attendant -birth attendants who attends birth out of health institution.

- Skilled birth attendant: Birth attendants who attend birth in the health institution with scientific skill and knowledge.

- Community diagnosis: It is quantitative and qualitative description of health status of citizen and the factor which influence the health. It identifies problem, proposes area for improvement and stimulate action.

- Health status: The health condition of the community, assessed on morbidity, mortality, disability and utilization of health services.

- Head of house hold: is a person with either sex, who is considered to be the head by other member of that house hold, for polygamous wife living in separate house hold, the house hold is considered to be head only.

- Maternal and Child Health: Include those who are aged 15-49 year women and those under five years' old children.

- Live birth: Number of infants born alive during the last 12 months including anyone who were born alive.

\section{Result}

\section{Scio demographic data}

The study consisted of 201 individuals found in 50 households. Of which 94 (46.77\%) of them were males, while $31.28 \%$ of them were under 14 years of old. Individual that couldn't read and write consisted of $19.9 \%$ on the other hand $1.6 \%$ of them were farmers (Table 1 ).

\section{Environmental sanitation}

All the studied houses had a roof that was made of sheet. $94.6 \%$ of the houses had smooth wall which is not cracked and scratched while the remaining $5.4 \%$ were scratched. $83.3 \%$ of studied houses had floor made of soil, and the rest $17.4 \%$ is made from cement.

During visiting, 30 (60.6\%) houses' window was opened. Half of them have been opened daily and the other $40.6 \%$ windows have 


\begin{tabular}{|c|c|c|c|c|c|}
\hline \multirow{6}{*}{ Age } & Year & $\mathbf{M}$ & $\mathbf{F}$ & Total & $\%$ \\
\hline & $0-4$ & 6 & 4 & 10 & 4.98 \\
\hline & $5-14$ & 25 & 28 & 53 & 26.3 \\
\hline & $15-24$ & 16 & 23 & 39 & 19.41 \\
\hline & $25-64$ & 44 & 46 & 90 & 44.78 \\
\hline & $>65$ & 3 & 6 & 9 & 4.48 \\
\hline \multirow{5}{*}{ Religion } & Orthodox & 94 & 107 & 201 & 100 \\
\hline & Muslim & - & - & - & - \\
\hline & Catholic & - & - & - & - \\
\hline & Protestant & - & - & - & - \\
\hline & Other & - & - & - & - \\
\hline \multirow[b]{2}{*}{ Ethnicity } & Amhara & 94 & 107 & 201 & 100 \\
\hline & Others & - & - & - & - \\
\hline \multirow{5}{*}{$\begin{array}{l}\text { Educational } \\
\text { status }\end{array}$} & Can't read \& write & 16 & 24 & 40 & 19.9 \\
\hline & Can read write & 9 & 9 & 18 & 8.96 \\
\hline & 1-8 grade & 24 & 31 & 55 & 27.37 \\
\hline & $9-12$ grade & 14 & 19 & 33 & 16.4 \\
\hline & Higher education & 19 & 26 & 45 & 22.39 \\
\hline \multirow{6}{*}{ Occupation } & Civil servants & 3 & 6 & 9 & 4.48 \\
\hline & Private worker & 9 & 5 & 14 & 6.97 \\
\hline & Merchants & 3 & 5 & 8 & 3.98 \\
\hline & Daily labor & 4 & 9 & 13 & 8.47 \\
\hline & Farmer & 2 & 1 & 3 & 1.6 \\
\hline & Others & 81 & 73 & 154 & 76.62 \\
\hline \multirow{6}{*}{ Marital status } & Single & 24 & 42 & 66 & 32.8 \\
\hline & Married & 25 & 26 & 51 & 25.38 \\
\hline & Divorce & 0 & 10 & 10 & 4.98 \\
\hline & Widow & 0 & 10 & 10 & 4.98 \\
\hline & Live separate & 0 & 1 & 1 & 0.5 \\
\hline & Not reach to marriage & 31 & 32 & 63 & 31.35 \\
\hline \multirow{4}{*}{ Monthly income } & $<500$ birr & 9 & 15 & 24 & 48.00 \\
\hline & 501-1000 birr & 7 & 5 & 12 & 24 \\
\hline & 1001-2500 birr & 5 & 1 & 6 & 12 \\
\hline & $>2500$ birr & 3 & 5 & 8 & 16 \\
\hline
\end{tabular}

Table 1: Socio-demographic status of Debre Markose 05 kebele individuals in 2013.

opened occasionally. From the total selected houses, $57.78 \%$ of them have an additional door to escape during emergency cases. Most of the houses $(91 \%)$ have enough light, from which $30.12 \%$ obtain morning light. $17.39 \%$ of the selected houses gain light afternoon and the rest $52.49 \%$ obtain both morning and afternoon light. Out of the studied houses $70.4 \%$ of them are separated from the neighboring house and the other $29.6 \%$ of them are joined with the nearby houses. Regarding the owner ship of the houses, $65.6 \%$ of them are private while the remaining is rented. Most of the family members sleep on bed and the rest sleep on floor ('medeb').

$89.22 \%$ of the selected households have kitchen of which $86.58 \%$ of them are separated from the main houses, and $12.8 \%$ are joined with the main houses. From 29 households only 2 (6.87\%) of them have kitchen with windows.

Regarding stove utilization, 30 houses holds $(60 \%)$ have traditional stove. From these 17 stoves (35.55\%) have chummy. From the selected houses only one house hold use electrical stove. 49 (98\%) households use wood, charcoal, can dung \& fuel gas for cooking. All households have electric supply.

Regarding latrine condition, 47(94\%) households have latrine while all have common latrine. 35(70.32\%) households do not have cover for their latrine. 22(44.5\%) households have good sanitation condition.

Regarding water supply, all households are suspired with the current water supply. Most households have (47) domestic animals. Household fly, flea, mosquito, rodent (rat) and bed bug are common rodents (Figure 2). These problems that need special attention on the health of the community of the selected households.

\section{Maternal and child health result}

In the study population, 50 of them were in the reproductive age group (15-49 years). Among 47 couples, 13 (6.47\%) and 30 (14.41\%) of them married in the age less than 18 and greater than 18 years respectively.

Among couples, 12(25.54\%) number of women gave birth in the age of less than 18 years old while 23 (48.94\%) of them gave birth between the age of 18-35 years old. No abortion case (legal and illegal) was found in the last 12 month.

Among the reproductive age group individual, 5(10\%) and 4(8\%) were pregnant and gave birth in past 12 months respectively. All of them gave birth in health institution. All pregnant mothers attained ANC services at least one times. When we see post natal care services at health facility, two of them within 2 days, one in first 7 days and one in the 42 days of delivery. 18 numbers of women used contraceptive, of which $12(85.4 \%)$ of them used Depo-Provera (Tables 2 and 3 ).

\section{Child health status}

In our community assessment there was $11(5.48 \%)$ under five children from the total 201 sample population (Table 4). Harmful traditional practice like Tonsillectomy, FGM and Tooth Extraction

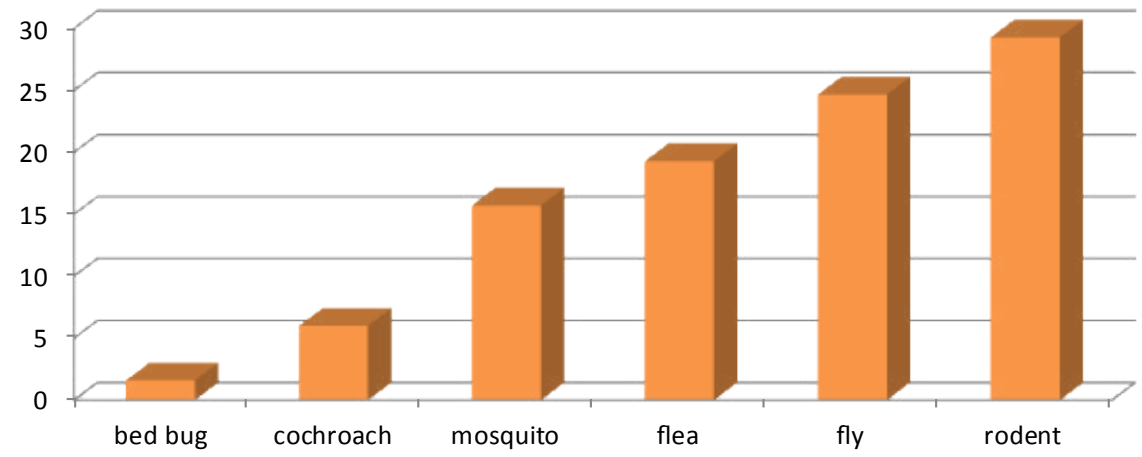

Figure 2: The magnitude of rodents and insects in Debre Markos town in 05 Keble in 2013. 


\begin{tabular}{|c|l|c|c|}
\hline No & Types of contraceptive methods & Frequency & Percentage \\
\hline 1 & Depo-Provera & 12 & 66.6 \\
\hline 2 & Oral contraceptive & 2 & 11.1 \\
\hline 3 & Nor plant & 2 & 11.1 \\
\hline 4 & IUCD & 1 & 5.5 \\
\hline 5 & Rhythmic periodic & 1 & 5.5 \\
\hline & Total & 18 & $100 \%$ \\
\hline
\end{tabular}

Table 2: The type of contraceptive use and frequency of these contraceptive in Debremarkose kebele 05 in 2013.

\begin{tabular}{|c|c|c|}
\hline S. No & TT Vaccination & Frequency \\
\hline 1 & TT1 & 20 \\
\hline 2 & TT2 & 16 \\
\hline 3 & TT3 & 14 \\
\hline 4 & TT4 & 13 \\
\hline 5 & TT5 & 7 \\
\hline
\end{tabular}

Table 3: Immunization status of reproductive age (15-49) women for tetanus in Debre Markose kebele 05 in 2013.

\begin{tabular}{|c|c|c|c|c|}
\hline S. No & Criteria & Age & No. & $\%$ \\
\hline \multirow{3}{*}{1} & \multirow{3}{*}{ Breast feeding } & $<6$ months & 2 & 18.18 \\
\cline { 3 - 5 } & & $6-24$ months & 8 & 72.73 \\
\cline { 3 - 5 } & & $>24$ months & 1 & 9.09 \\
\hline \multirow{2}{*}{2} & \multirow{3}{*}{ Complementary feeding } & $<6$ months & 1 & 9.09 \\
\cline { 3 - 5 } & & at 6 months & 9 & 81.82 \\
\cline { 3 - 5 } & & $>6$ months & 1 & 9.09 \\
\hline
\end{tabular}

Table 4: The length of breast feeding in less than 5 year children in Debre Markose kebele 05 in 2013.

weren't practiced in selected households (Table 5). Dropout rate of penta and meseales was $33.34 \%$.

\section{Morbidity status}

There were two individual who were physically disable due to injection error and fracture. AS we interviewed the selected house hold in Debre Markos town 05 kebele almost all the houses respond that if one of the members of household is sick, they tried to go to health institutions (Table 6).

\section{Discussion}

According to our study $94 \%$ of households had latrine, while EDHS 2011data showed relatively lower number of households $(62 \%$ of house hold) $[8,10,11]$. This may be due to adequate health education about latrine construction and utilization by co- coordinating health extension worker, health development army, health center, also health office. In our study $52 \%$ and $36 \%$ of house hold had no solid and liquid waste disposal pit respectively, but according to Amhara regional state health be roué 2012 annual reported slow performance in inspection of solid and liquid waste disposal pit was $84 \%$ and $88 \%$ respectively $[9,12,13]$.

According to our study there is no maternal death related to pregnancy and delivery but the maternal mortality rate of Ethiopia is 676 deaths from 100,000 live births according to EDHS 2011[8,14]. The result may indicate that health extension worker, woreda health office, hospital and other supporters of community create awareness on maternal health.

In our finding, measles fully immunization coverage was low (60\%). This may be due to urban health extension workers didn't give immunization service, and low community awareness about immunization default. There was poor practice about exclusive breast feeding and complementary feeding which showed, $9 \%$ of infant start complementary feeding before six months while $9 \%$ of not started complementary feeding at the age of $>6$ month. This indicates the awareness of the community about exclusive breast feeding \& complementary feeding is low.

ANC follow-up was good (100\%), on the contrary EDHS 2011 report showed, it was $34 \%[8,15]$. This may be due to increase awareness of the pregnant women.

In our study show, skill birth attendant is high/100\%/ but in EDHS/2011/ it was $10 \%[8,16]$. This may be due to the cooperative work of health care professionals by giving information regarding to mother and child health.

This study found, marriage before the age of 18 yrs was $6.47 \%$, but EDHS 2011 report found 63\% [17,18]. This result may be due to strong legal issue that prohibits marriage before age 18 years and most females spent their time on school.

From the interview, harm full traditional practice was not exercised. This indicates there was community awareness in the negative health impact of harmful traditional practice.

\section{Conclusion}

Most health extension packages were not properly utilized. Although all deliveries were under taken in health institution, vaccination and complementary feeding of the child were not taken properly and in appropriate time. Asthma and gastritis were most

\begin{tabular}{|c|c|c|c|c|}
\hline S. No & Types of vaccination & No infant $<1$ yrs & Vaccination infant & $\%$ \\
\hline \multirow{4}{*}{1.} & Polio 0 & \multirow{14}{*}{5} & 1 & 20 \\
\hline & Polio 1 & & 3 & 60 \\
\hline & Polio 2 & & 3 & 60 \\
\hline & Polio 3 & & 2 & 40 \\
\hline \multirow{3}{*}{2.} & Penta 1 & & 3 & 60 \\
\hline & Penta 2 & & 3 & 60 \\
\hline & Penta 3 & & 2 & 40 \\
\hline 3. & BCG & & 3 & 60 \\
\hline 4. & Measles & & 2 & 40 \\
\hline \multirow{3}{*}{5.} & PCV 1 & & 2 & 40 \\
\hline & PCV 2 & & 2 & 40 \\
\hline & PCV 3 & & 2 & 40 \\
\hline 6 & PAB & & 2 & 40 \\
\hline 7 & Fully immunized & & 2 & 40 \\
\hline
\end{tabular}

Table 5: Vaccination of infants and frequency of each vaccination in Debre Markos 05 kebele in 2013

\begin{tabular}{|c|c|c|c|}
\hline S. No & Types of disease & Frequency & Percent \\
\hline 1 & Headache & 1 & 8.33 \\
\hline 2 & Common cold & 1 & 8.33 \\
\hline 3 & Hypertension & 1 & 8.33 \\
\hline 4 & Heart failure & 1 & 8.33 \\
\hline 5 & HIV & 1 & 8.33 \\
\hline 6 & Asthma & 2 & 25 \\
\hline 7 & Diabetes mellitus & 1 & 8.33 \\
\hline 8 & Gastritis & 2 & 25 \\
\hline 9 & Idiopathic & 1 & 8.33 \\
\hline 10 & Pneumonia & 1 & 8.33 \\
\hline & Total & 12 & \\
\hline
\end{tabular}

Table 6: List of disease other than diarrheal diseases that occur in the last two weeks in Debre Markos Town administration, kebele 05 in 2013. 
Citation: Gelaw BK, Tegegne GT, Bizuye YA (2014) Assessment of Community Health and Health Related Problems in Debre Markos Town, East Gojjam, Ethiopia, 2013. J Biosafety Health Educ 2: 125. doi:10.4172/2332-0893.1000125

frequently encountered disease. Harmful traditional practice was exercised, especially early married. There is High dropout rate of penta and measles and also low TT vaccine coverage.

\section{Recommendation}

The following recommendations were forwarded.

1. The town administration and woreda health office with concerned stakeholders should work to improve the awareness of the community about proper placement and utilization of liquid and solid waste burning materials, kitchen and latrine utilization, and alternate energy source for cooking.

2. The health office stake holder should work to create awareness about immunization.

3. Health care providers:- to teach hand washing.

4. for those working in Family planning:-to teach the different forms of family planning.

\section{Acknowledgements}

We are very grateful to our college staff members for unreserved guidance and constructive suggestions and comments from the stage of proposal development to this end.

We would like to thank Debire Markos University for supporting the budget which required for this research.

Finally our deepest gratitude goes to Debire Markose kebele 05 administration offices that help and allow us in collecting and gathering data from the households.

\section{References}

1. National Center for Health Statistics (2006) Health, United States, with chart book on trends on the health of Americans. Hyattsville, MD.

2. US (2005) Bureau of the Census. Statistical Abstract of the United States: 2006. Washington, DC

3. Holveck JC, Ehrenberg JP, Ault SK (2007) Prevention, control, and elimination of neglected diseases in the Americas: pathways to integrated, interprogrammatic, inter-sectoral action for health and development. BMC Public Health 7: 6 .
4. Measure DHS: DHS surveys and national reports on health situations in different African countries.

5. Odeyemi AO, Nixon J (2013) Assessing equity in health care through the national health insurance schemes of Nigeria and Ghana: a review-based comparative analysis. Int J Equity Health 12: 9

6. Ssengooba F, Rahman S, Hongoro C, Rutebemberwa E, Mustafa A, et a (2007) Health sector reforms and human resources for health in Uganda and Bangladesh: mechanisms of effect. Human Resource Health 5: 3.

7. WHO (2008) Community-directed interventions for major health problems in Africa: a multi-country study, Geneva, Switzerland: Special Programme for Research \& Training in Tropical Diseases (TDR) World Health Organization.

8. Ethiopia health demography survey 2011

9. Debre Markose (2013) Debre markos ketma health office, health extension program annual report, 23-25.

10. Department of Community Health (1988) Team Training Programme Manual, Part II. Jimma: Jimma Institute of Health Sciences 1-26.

11. Department of Community Health (1996) Manual for Student Research Project Jimma: Jimma Institute of Health Sciences 1-71.

12. Woodward C (1992) Some reflections of evaluations of outcomes of innovative medical education Programme during the practice period Annals of CommunityOriented Education 5: 181-191.

13. WHO study groups (1993) Increasing the relevance of education for health professionals. WHO Technical Report Serves No 838.

14. Kamien M, Boelen C, Heck J (1999) Measuring social responsiveness of medical schools. Education for Health, 12: 9-19.

15. Moja EA, Ghetti V (1995) Assessing performance of medical schools. Annals of Community-Oriented Education, 8:247-253.

16. Department of Community Health (1987) Community Based Training Program Manual, Part I. Jimma: Jimma Institute of Health Sciences 1-63.

17. Seefeldt M (2000) Evaluating community-based health programmes. In Schmidt $\mathrm{M}$ et al., (ed). Handbook of community-based education: theory and practices. Maastricht: Network Publications 345-360.

18. Sims P (1997) Community-based education-the Zambian experience. Education for Health 10: 301-310 